\title{
Fine-Needle Aspiration Followed by Core-Needle Biopsy in the Same Setting: Modifying Our Approach
}

\author{
Amani A. Joudeh Sameera Q. Shareef Mousa A. Al-Abbadi \\ Department of Pathology and Laboratory Medicine, King Fahad Specialist Hospital, Dammam, \\ Kingdom of Saudi Arabia
}

\section{Key Words}

Fine-needle aspiration · Core-needle biopsy · Combined approach $\cdot$ Rapid on-site specimen evaluation

\begin{abstract}
Fine-needle aspiration biopsy (FNAB) is a well-established initial diagnostic tool. However, in some instances limitations and shortcomings arise, making it insufficient for determining a specific diagnosis. Consequently, patients have to undergo another diagnostic procedure. The second procedure is either repeat FNAB, core-needle or open biopsy, and can be inconvenient and costly. In some centers, the FNAB is immediately followed by core-needle biopsy (CNB) in the same setting after assuring adequacy on the initial FNAB utilizing rapid on-site specimen evaluation (ROSE). It is argued that implementing such an approach will eventually have additional critical advantages that include the following: (a) it is more convenient to patients to have both procedures in one visit, (b) the tissue procured by both procedures will be more adequate, enabling cytopathologists to reach an accurate diagnosis, and (c) it is ultimately a cost-effective approach if we take into consideration the avoidance of a potential second more invasive diagnostic procedure. Since we
\end{abstract}

are living in an era of patient-centered medicine coupled with cost-cutting strategies, we present here a brief review of the topic with analysis of this alternative approach, review of the pertinent literature and shed light on a few scenarios that justify this approach.

(c) 2016 S. Karger AG, Basel

\section{Introduction}

Fine-needle aspiration biopsy (FNAB) is widely accepted as an initial diagnostic tool for almost all body lesions, benign or malignant. FNAB is usually obtained using 22- to 27-gauge needles and the procedure provides a sample for cytological examination, with possible cell block preparation. It is a simple and relatively noninvasive procedure which requires a skilled aspirator along with the routine use of syringes, needles and stains. Moreover, FNAB is a very safe technique with negligible complications $[1,2]$. In most instances, and specifically for palpable lesions, FNAB does not need major preprocedure preparations and radiology guidance, so it can be performed in the clinic without reserving a place in the radiology unit or operating rooms.

\section{KARGER}

E-Mail karger@karger.com www.karger.com/acy
(C) 2016 S. Karger AG, Basel

0001-5547/16/0601-0001\$39.50/0
Correspondence to: Prof. Mousa A. Al-Abbad

Department of Pathology and Laboratory Medicine

King Fahad Specialist Hospital

Dammam (Kingdom of Saudi Arabia)

E-Mail alabbadima@yahoo.com 
FNAB with rapid on-site specimen evaluation (ROSE) provides an immediate assessment of adequacy and quick lesional diagnosis in most instances, which allows the clinicians to discuss the diagnosis with the patient without any delay. Furthermore, involvement of the cytopathology team with on-site evaluation ensures a proper clinical correlation and optimizes the handling of the specimen. When ROSE is utilized, it allows the provision of samples for ancillary studies, such as microbiological analysis, molecular studies, flow cytometry, cytogenetics, and sometimes electron microscopic studies. This triaging approach usually depends on the preliminary diagnosis performed utilizing ROSE $[3,4]$. Nasuti et al. [5] demonstrated that the average nondiagnostic rate of FNAB dropped from 20 to $0.1 \%$ by the addition of on-site evaluation. Other investigators have documented a high accuracy rate of $96 \%$ of FNAB when onsite interpretation was performed during the procedure $[5,6]$. In their analysis of CT-guided core biopsies of solid organs, Schoellnast et al. [7] demonstrated the critical importance of on-site assessment by cytopathologists. They concluded that FNAB without on-site cytopathological evaluation does not yield better sensitivity or specificity when compared to core-needle biopsy (CNB) alone.

The availability of ROSE is extremely important regardless of the specimen type. It can be very helpful whether the intended procedure is FNAB alone, $\mathrm{CNB}$ alone, or combined.

The introduction of the cell block technique increased the diagnostic accuracy of FNAB. The value of a cell block as complementary to cytological assessment is well established in many anatomical sites [8-11]. It essentially provides more tissue material that could be used for ancillary testing, such as polymerase chain reaction, fluorescent in situ hybridization and immunohistochemistry, consequently increasing the sensitivity and specificity of FNAB. In addition, the availability of a cell block provides more architectural details to the specimen (fig. 1). In their recent review, Jain et al. [12] provided a detailed description of the cell block technique in cytopathology with a comprehensive review of its preparative methods, utility in diagnosis and role in ancillary studies.

Despite these facts, FNAB occasionally falls short of providing adequate material to enable the cytopathologists to render an accurate and detailed comprehensive diagnosis. Adequate cytological diagnosis may not be given due to a small sample size, lack of cell block material for ancillary studies and the absence of a detailed architectural pattern. In these situations, a repeat FNAB, CNB or open surgical biopsy may be necessary to obtain adequate tissue for a more specific and reliable diagnosis. In addition to its added cost, this process is time-consuming and is also inconvenient to the patient since it requires another procedure with exposure to either local or general anesthesia. To overcome these constraints, some centers currently perform CNB complementary to FNAB in a single diagnostic procedure. This review aims to address the potential benefits for modifying the diagnostic approach to encompass FNAB immediately followed by a $\mathrm{CNB}$ in one setting.

\section{Limitations of FNAB}

Although the increased sensitivity and accuracy of FNAB may decrease the need for CNB, FNAB may not provide adequate cellular or architectural details in certain types of lesions $[11,13]$. Therefore, in a few circumstances, obtaining a tissue biopsy may be mandatory.

The diagnostic accuracy of FNAB may be variable depending on the skills and experience of the operator, hence it is really aspirator dependent. In some instances the amount of tissue obtained may not be sufficient enough to prepare a cell block, preventing the pathologist from performing the necessary diagnostic ancillary tests required for an accurate diagnosis. These include, but are not limited to, immunohistochemistry, microbiological analysis, and molecular and cytogenetic studies. For instance, in thyroid lesions, FNAB has some adequacy limitations whereby unsatisfactory rates have been reported to be between 4 and 21\% [14-19], while the rate of indeterminate diagnosis is $3-18 \%$ even with ultrasound guidance $[17,18,20]$. The diagnostic sensitivity and specificity of ultrasound-guided FNAB of the thyroid are approximately 83 and $92 \%$, respectively [21]. Although cell block preparation is not a routine step in thyroid aspiration cases, certain cases would benefit and the availability of cell block has the potential to limit the number of indeterminate interpretations and may provide material for molecular studies. However, other investigators, for whom the implementation of molecular analysis is characterized by a reasonable accuracy and availability in their institution, were successful in evaluating molecular studies on material obtained through fine-needle aspirates of thyroid [21-25].

In breast lesions, FNAB can be inconclusive in up to $30 \%$ of cases, with $20 \%$ being reported as inadequate and $10 \%$ being suspicious for malignancy [26]. This can be attributed to certain types of invasive ductal carcinoma, like 

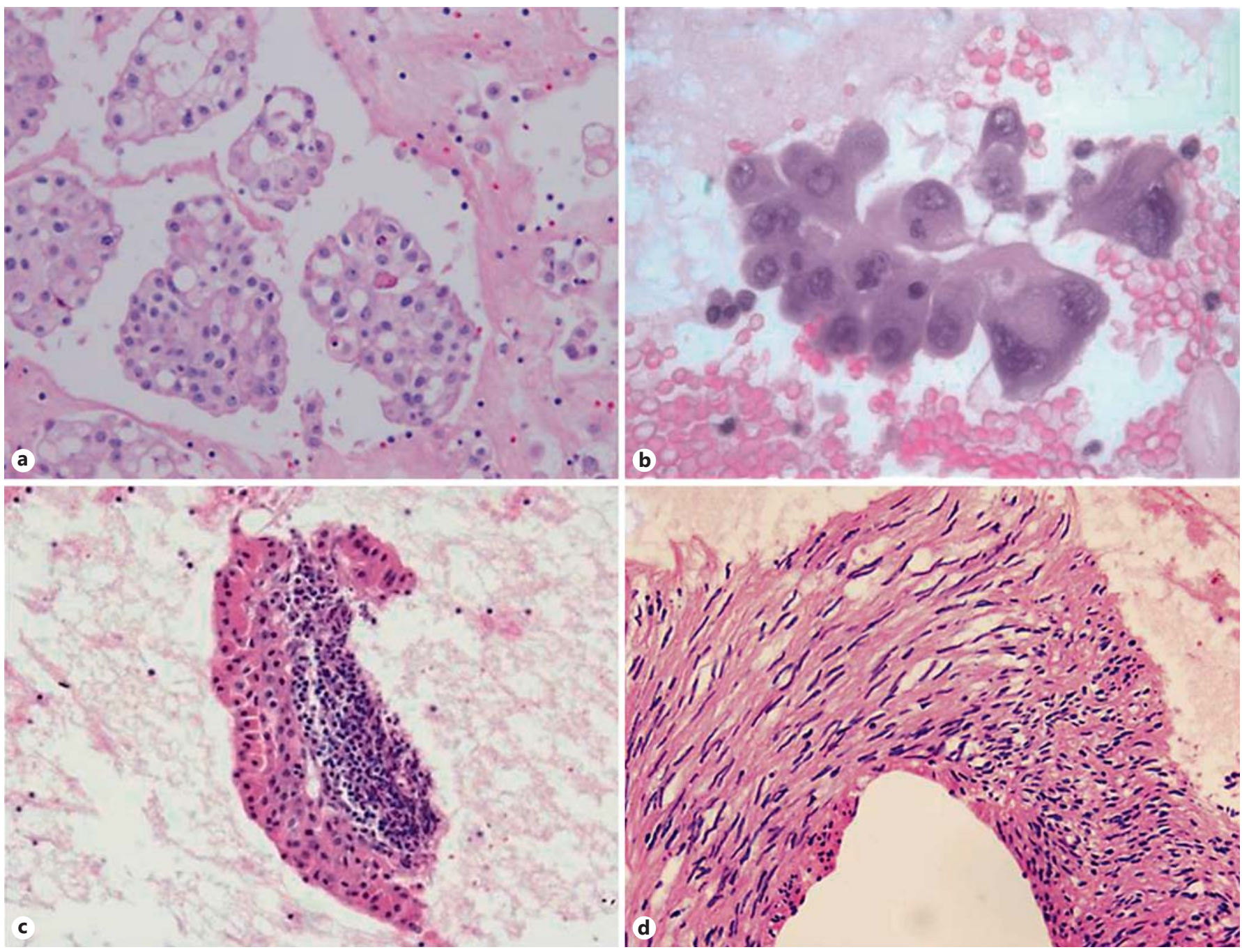

Fig. 1. Multiple cell blocks of different aspirates from different organs: mammary carcinoma (a), complex renal cyst that proved to be cystic nephroma (b), Warthin's tumor of parotid mass (c) and gastrointestinal stromal tumor through endoscopic ultrasound-

guided fine-needle aspiration (d). These cell blocks are as good as tissue biopsies exhibiting the appropriate features complementing the findings in the smears and are amenable to multiple ancillary studies.

scirrhous-type and lobular carcinoma which are sometimes difficult to diagnose by FNAB $[2,27,28]$. Although it is well known when evaluating mammary carcinoma that the axillary node status is best tackled by aspirate smears, FNAB alone in many cases cannot confirm that. Moreover, FNAB alone cannot confirm the presence of tumor invasion and cannot be used to differentiate between invasive and in situ neoplasia [29-31]. In addition, low-grade breast lesions, such as atypical ductal hyperplasia, low-grade ductal carcinoma in situ and tubular carcinoma, cannot be accurately diagnosed using this modality alone [32-35].

FNAB in many cases does not provide material to allow a full architectural evaluation which makes it difficult whenever the architecture is needed to make a specific diagnosis, such as certain types of lymphomas and benign nonneoplastic lung diseases (fig. 2). Besides, the relationship between the lesion and the surrounding tissues cannot be evaluated properly using an FNAB modality alone. One additional major limitation of FNAB is the inability to make an accurate interpretation for specific benign conditions in some organs. For instance, certain benign lymphoid lesions cannot be made accurately by FNAB, such as infectious mononucleosis and Castleman disease 


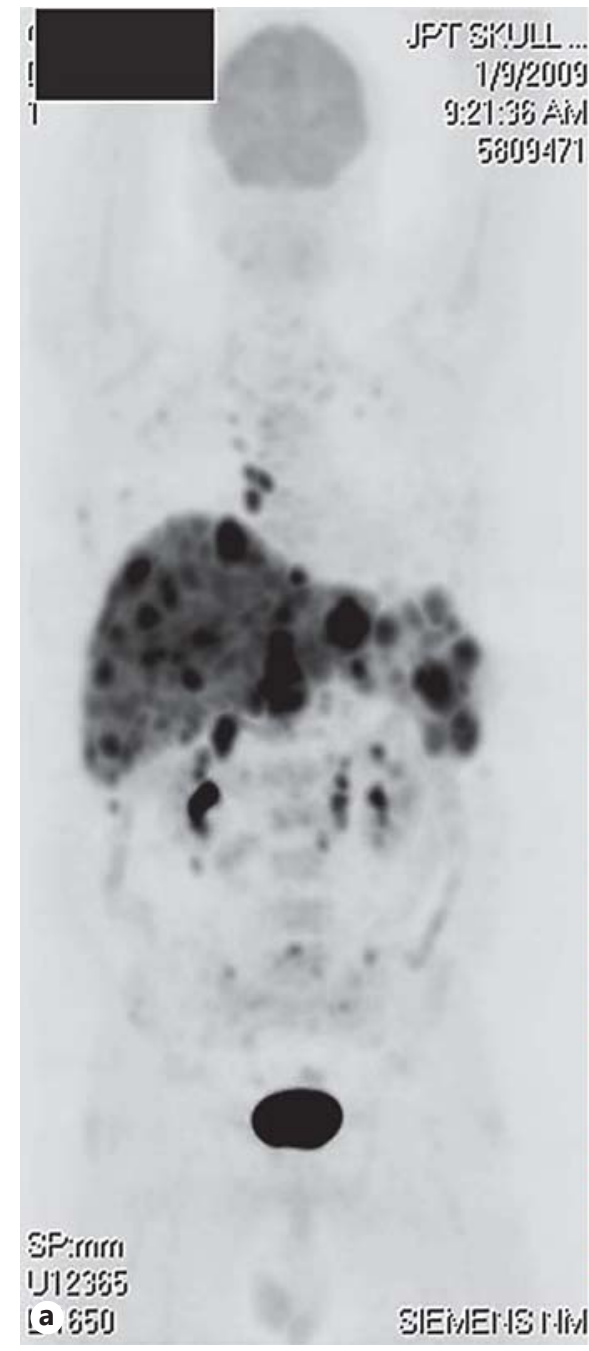

Fig. 2. These images are from a 56-year-old male who presented with loss of weight and general weakness. He was found to have hepatomegaly and a PET scan (a) showed extensive infiltration by highly active nodules. FNAB was performed revealing numerous atypical

$[36,37]$. In one study aimed to assess the diagnostic value of CNB relative to FNAB in patients with pneumonia and mimics of pneumonia, which is a major differential diagnosis of lung masses, the authors found that a specific diagnosis was made in only 7 out of 41 patients (17\%) with thoracic benign lesions [38].

In their study performed on FNAB of soft tissue lesions, Bennert and Abdul-Karim [39] showed that FNAB was unsatisfactory in 44 out of 117 cases (37\%), of which $22(50 \%)$ had a corresponding CNB diagnosis. CNB is more accurate than FNAB in diagnosing and subtyping soft tissue lesions. Table 1 summarizes the aforementioned limitations.

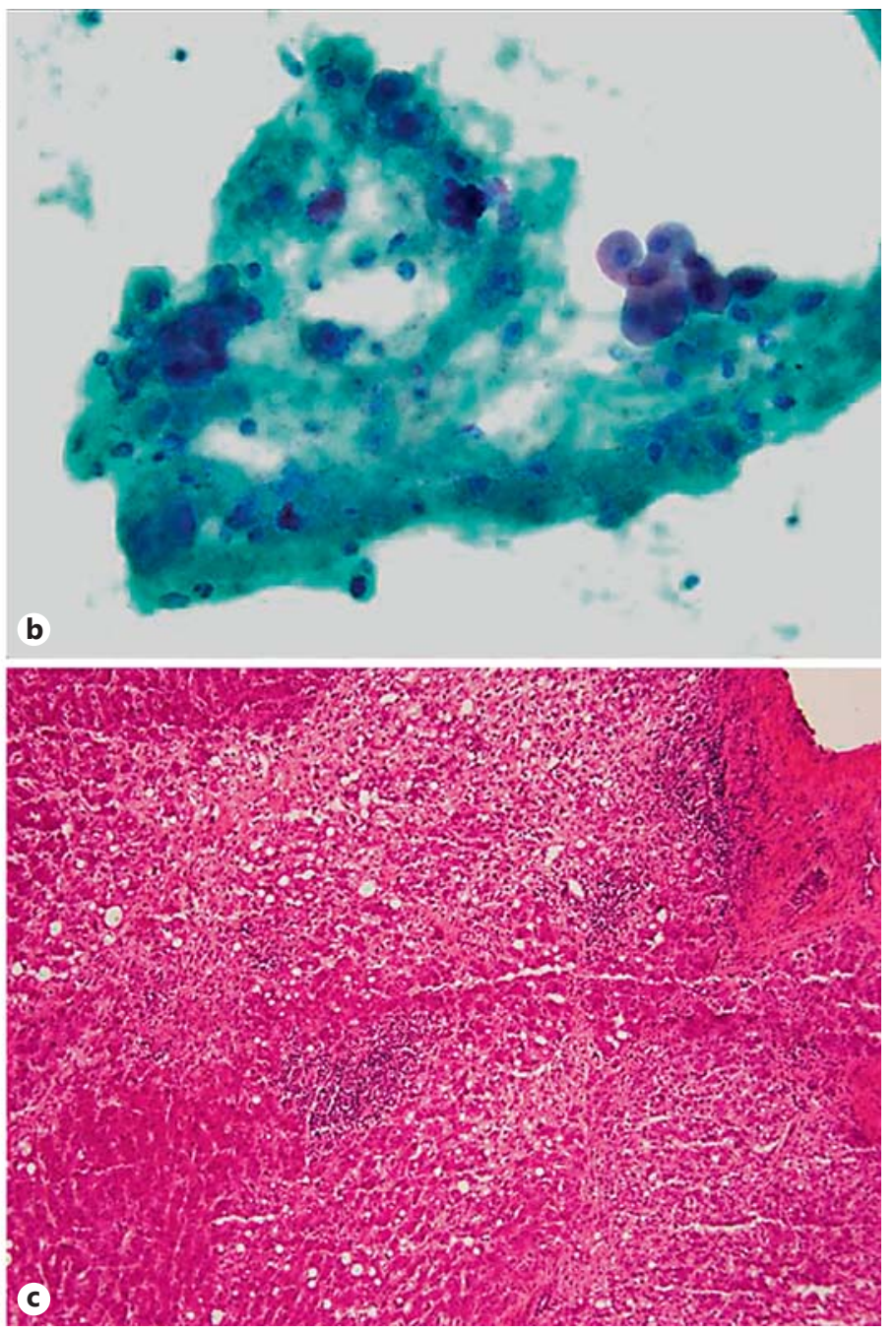

large lymphoid cells (Papanicolaou-stained smear; b) surrounded by many smaller bland-appearing lymphoid cells. A core biopsy followed by a laparoscopic wedge liver biopsy (c) was needed to make the diagnosis of T cell-rich B cell non-Hodgkin lymphoma.

\section{CNB as an Alternative to FNAB}

CNB is obtained using large needles (14-18 gauge) and it primarily provides tissue for histological evaluation. In most cases where FNAB is indeterminate, CNB can help obtain a reliable histological diagnosis. This can easily be achieved by applying local anesthesia for those patients who are not surgical candidates or refuse surgery. Moreover, CNB provides an alternative option in situations where ROSE is not available, such as when there is a very busy pathology practice and in small primary care centers with no pathology services. In comparison to open surgical biopsy, $\mathrm{CNB}$ is less invasive and 
Table 1. Limitations of FNAB

It is operator dependent and requires certain skills and experience to ensure adequate sampling

May not provide adequate material to prepare a cell block which limits the ability to perform diagnostic ancillary studies

Lack of architecture even with well-prepared cell blocks

Absence of the spatial relationship between the lesion and the surrounding tissues and inability to assess lesion capsular invasion by the tumor

Inability to specify a benign pathological process in some organs (benign lymphoid diseases, benign soft tissue lesions and nonneoplastic lung diseases)

Inability to differentiate invasive from in situ mammary carcinoma

Difficulty of assessing low-grade and borderline lesions in some organs (breast and soft tissue)

Certain types of lymphomas need tissue sampling

Table 2. Advantages of $\mathrm{CNB}$ as an alternative to FNAB

Less operator dependent (most radiologists and interventional radiologists are trained to perform the procedure)

Provides adequate material for histologic evaluation and to perform diagnostic ancillary studies

CNB enables assessment of the histological architecture and preserves the relationship with tissue surrounding the lesion, enabling the assessment of capsular and adjacent tissue invasion

$\mathrm{CNB}$ is superior to FNAB in specifying some benign pathological processes in some organs (benign lymphoid diseases, benign soft tissue lesions and nonneoplastic lung diseases)

Invasive and in situ mammary carcinomas can be easily differentiated by CNB

Better assessment of borderline and low-grade lesions, especially breast and soft tissue lesions

Immediate adequacy assessment and tissue triaging can be achieved by touch imprints of core tissue by a cytotechnologist on site, which makes it a convenient approach when a cytopathologist is not available

is usually done in a single pass that hopefully samples the lesion. In addition, CNB provides larger tissue samples compared to FNAB. If the needle successfully penetrates the nodule, $\mathrm{CNB}$ is less operator dependent and enables the assessment of the histological architecture and keeps the relationship to surrounding adjacent tissues avail-
Table 3. Shortcomings of CNB

Needs a radiologist and privileged clinician to perform the procedure

Needs local anesthesia that may be less convenient for the patient and clinician

More invasive than FNAB, with more complications such as bleeding, infection, tumor seeding, pneumothorax and others

Processing and preparation of the biopsy slides takes more time

More expensive than FNAB

More labor-intensive

able in most circumstances (table 2 summarizes the aforementioned points).

However, the performance of $\mathrm{CNB}$ has a few disadvantages, one being that it needs a radiologist or a clinician with such privileges to be available, which increases the cost of the procedure. Although CNB performed by experienced radiologists and others is a safe procedure, it is still more invasive than FNAB and has the potential of more serious complications, such as bleeding, infections and pneumothorax. One of the most serious complications of this procedure is malignant seeding of the tumor in the needle tract, which is less documented in FNAB [40-43]. In addition, local anesthesia is less convenient to both the patient and the clinician, and it takes a longer time to prepare for the procedure and to obtain the results. CNB is a more expensive procedure as it needs processing, cutting and staining. It was found that the cost of $\mathrm{CNB}$ is approximately 3 times more than FNAB alone [44]. Table 3 summarizes the shortcomings of CNB.

\section{Approaching Masses by FNAB Immediately Followed by CNB (Explaining the Approach)}

The patient needs to secure an appointment with the FNAB/CNB clinic or interventional radiology department. The procedural technique should be explained to the patient with emphasis on possible complications of the process, as a larger needle is used to obtain the biopsy, followed by acquiring appropriate signed consent. Initially, one FNAB pass is tried to make sure the lesion is targeted utilizing ROSE evaluation to assure proper sampling. If the first pass is adequate, and based on the initial impression, extra material can be taken for ancillary studies if needed (flow cytometry, culture and others). Finally, 
Fig. 3. Algorithm of the fine-needle aspiration and core combined approach.

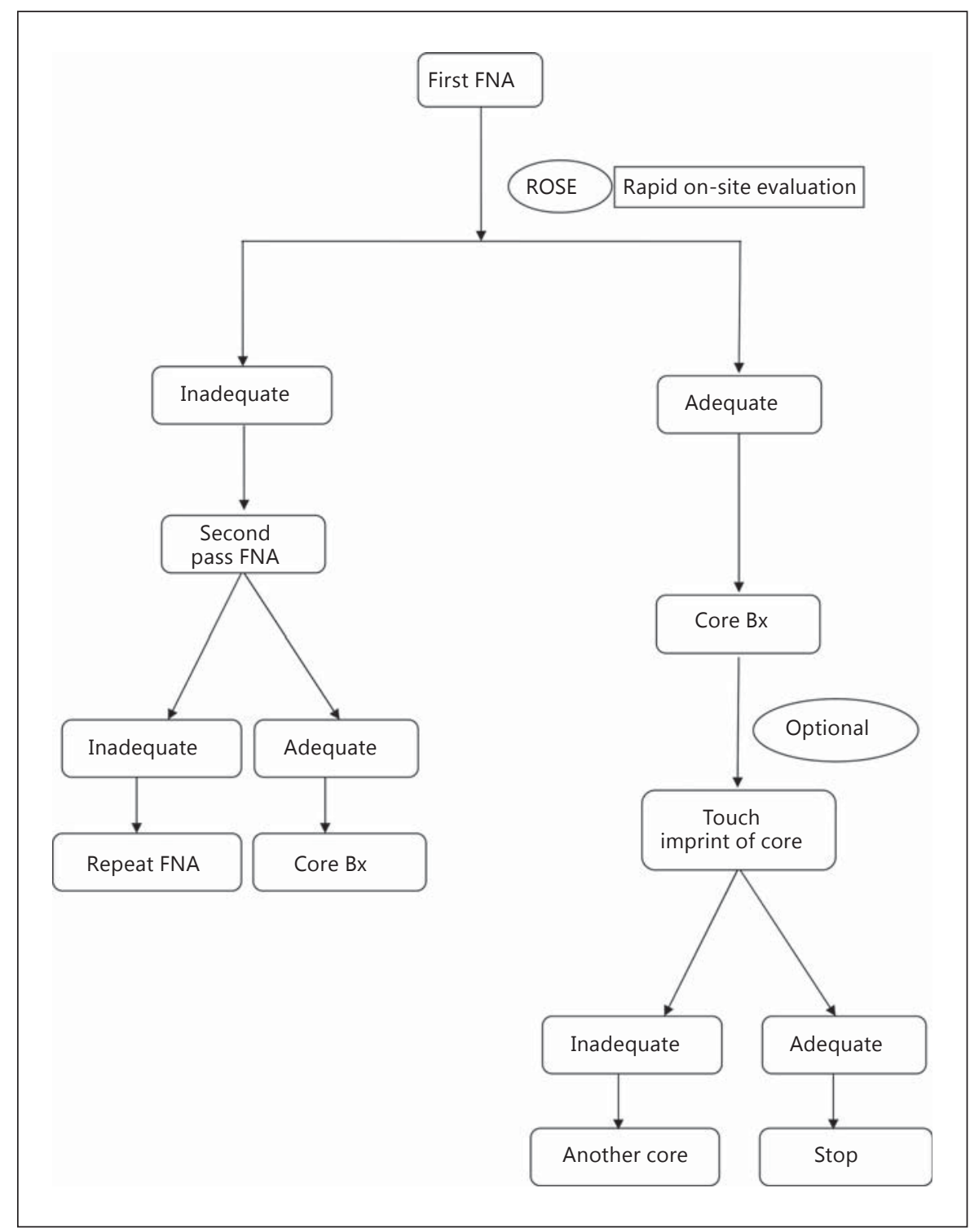

a CNB is obtained for further evaluation of the lesion. The entire process is performed in one setting with no additional inconveniences to both the patient or the operator of the procedure (fig. 3 ).

\section{Advantages of the Combined Approach}

Multiple studies have confirmed the effectiveness of the combined approach in increasing the accuracy of diagnoses of body lesions, especially small lesions [45-47]. Each technique (FNAB and CNB) plays a complementary role to the other in procuring satisfactory material for tis- sue and ancillary studies, and to minimize the rate of false-negative and false-positive results. Although both procedures have comparable sensitivity and specificity rates for diagnosing malignant lesions, as has been proven by multiple studies, adding CNB to the FNAB procedure will improve the diagnostic yield in many body lesions. Furthermore, CNB is superior to FNAB for rendering a specific diagnosis for benign lesions and certain malignant processes [12, 48-50].

In their study on head and neck lesions, Kraft et al. [51] found that $\mathrm{CNB}$ was superior to FNAB in a few aspects - providing a specific diagnosis, identifying true neoplasms and detecting malignancy. In this study, the 

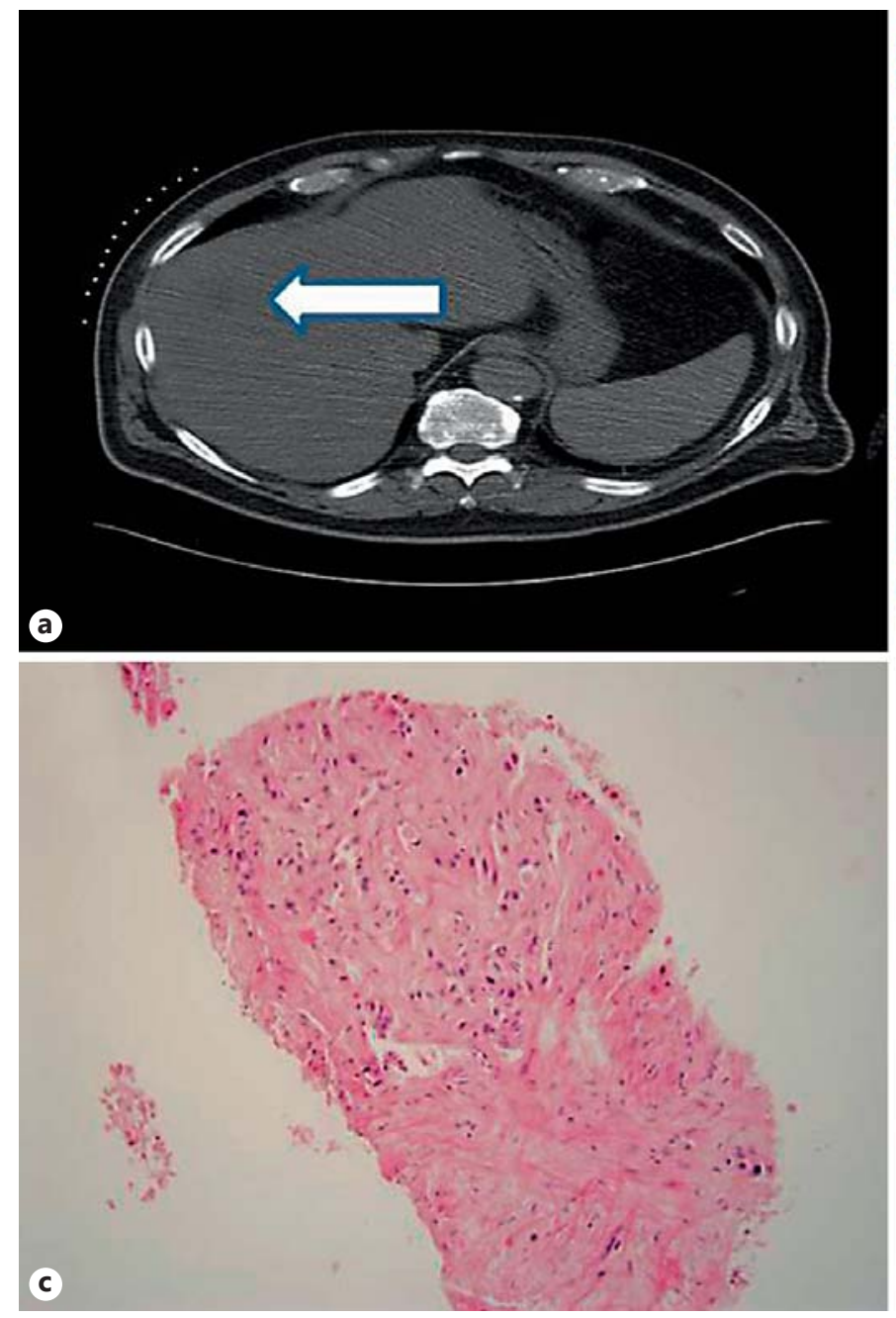

Fig. 4. These images are from a 65-year-old male patient who was found to have an ill-defined lesion in the right lobe of the liver (a) by CT scan. CT-guided fine-needle aspiration revealed suspicious clusters of cells with a probable necrotic background (b). A core biopsy was immediately done which revealed a moderately to

investigators compared the results obtained by CNB that was performed immediately before the surgical excision of the lesion and compared these with a prior FNAB diagnosis in 68 patients with head and neck masses. CNB was able to provide a specific diagnosis in 90 versus $66 \%$ obtained by FNAB. CNB was $100 \%$ accurate in identifying true neoplasms versus $93 \%$ identified by FNAB. They also reported that $99 \%$ of cases of malignancy were detected by CNB versus $90 \%$ detected by FNAB. However, the authors concluded that ultrasound and FNAB should remain the initial diagnostic tools for head and neck lesions. They also recommended utilizing the core biopsy approach as a substitute if FNAB fails to provide a diag-

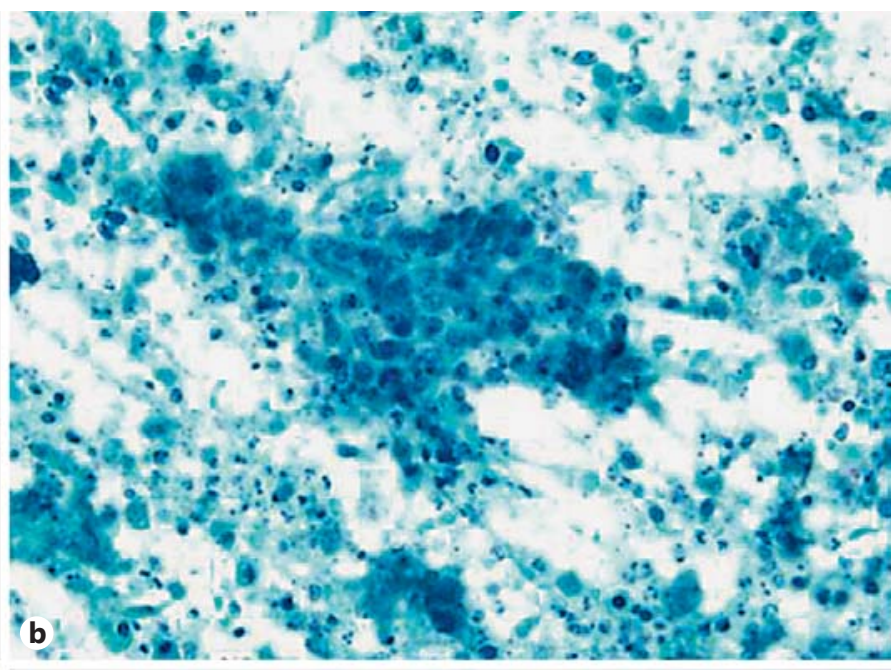

d

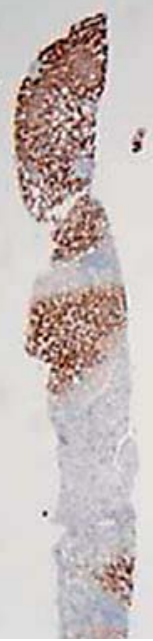

poorly differentiated adenocarcinoma (c) which proved to be lung primary by immunohistochemistry, CK7+ and TTF- $1+(\mathbf{d})$. Note that the core on the right did not contain a tumor, while the one on the left did.

nosis or in those patients where surgery is not an optimal option. Therefore, utilizing the combined approach in the same setting may provide us with optimum results.

Gong et al. [52] evaluated FNAB and CNB specimens of intrathoracic lesions. The authors compared the diagnostic accuracy of 362 FNABs and the concurrent CNB results that were performed in the same visit to the final diagnosis. The authors found that both FNAB and CNB had similar diagnostic accuracies for malignant tumors (85.1 and $86.7 \%$, respectively), especially for malignant epithelial tumors. However, for nonepithelial malignant tumors like sarcomas and lymphomas, CNB yielded a better diagnostic accuracy than FNAB alone (96 vs. 77\%, re- 

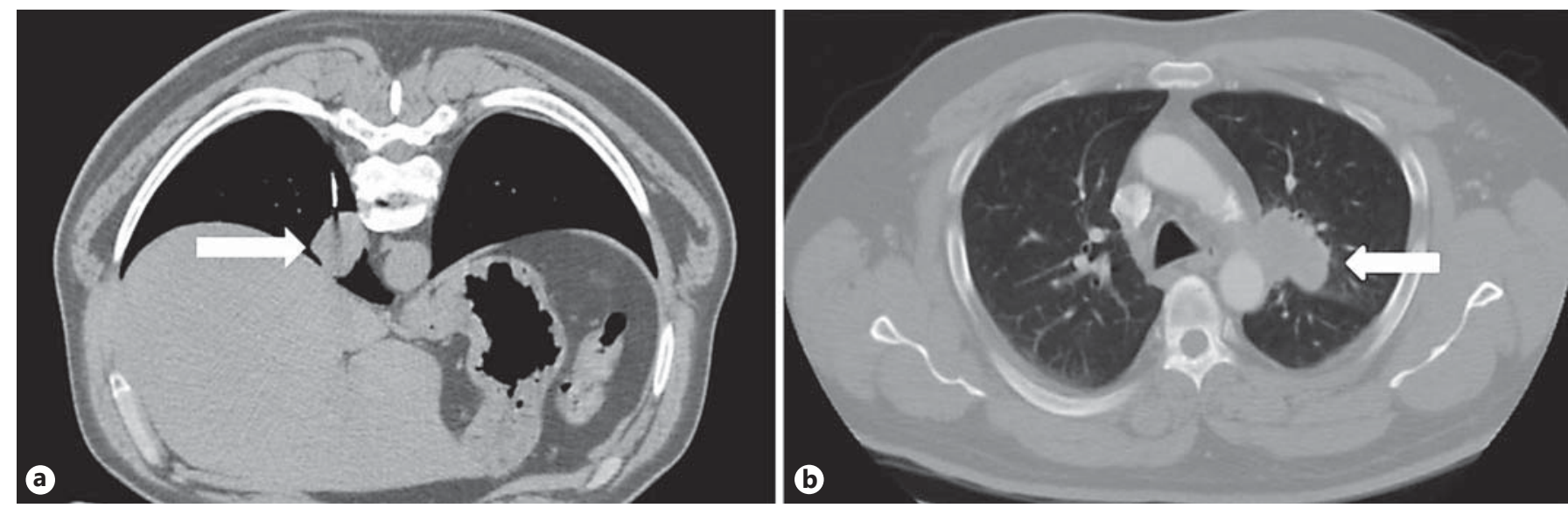

Fig. 5. Images from a 54-year-old male patient who was found to have 2 lung lesions. The lesion on the right side (a, white arrow) was well-circumscribed while the one on the left side (b, white arrow) was ill defined.

spectively). They demonstrated that by reviewing the results of FNAB and CNB together, the diagnostic accuracy of malignancy improved from 85 and 86.7 to $95.2 \%$. The same study showed a higher discrepancy in the diagnostic accuracy of FNAB and CNB in benign lung lesions. FNAB yielded a proper diagnosis in $40 \%$ of the benign cases, while $92 \%$ were diagnosed properly by CNB. The diagnostic accuracy increased to $96 \%$ by using both modalities together. These findings were supported by other studies emphasizing that $\mathrm{CNB}$ is superior to FNAB in diagnosing benign lung diseases [12, 48-50]. Thanos et al. [38] found that thoracic $\mathrm{CNB}$ provides a specific diagnosis in $87.5 \%$ of cases with pneumonia and mimics of pneumonia, compared to $20.83 \%$ diagnosed by FNAB. However, it is worth mentioning that recent studies have demonstrated success in the diagnosis and subtyping of lung carcinomas utilizing an FNAB approach alone [53-56].

Yang and Damron [57] confirmed the increased diagnostic accuracy of CNB over FNAB in musculoskeletal lesions, particularly in benign cases. This study, among others, emphasized that subclassification and grading of soft tissue lesions was achieved more accurately by $\mathrm{CNB}$ $[57,58]$. In their soft tissue study, Bennert and AbdulKarim [39] demonstrated that the unsatisfactory FNAB results of 22 cases were further clarified and specified by CNB (15 sarcomas, 2 fibromatosis and 5 benign lesions). Seven of the sarcoma cases that were diagnosed by FNAB were further subtyped by $\mathrm{CNB}$. In their study that aimed to identify the diagnostic accuracy of FNAB and CNB in diagnosing desmoid tumors, Dalén et al. [59] showed that 35 out of $69(50.7 \%)$ cases were diagnosed by FNAB and 24 out of $26(92.3 \%)$ cases were diagnosed by CNB. These findings confirm that $\mathrm{CNB}$ is more reliable than FNAB in diagnosing soft tissue lesions, and using the two modalities together would significantly improve the diagnostic accuracy in soft tissue lesions $[39,57,59]$.

The sensitivity of diagnosing breast cancer in one study increased from $80 \%$ for FNAB alone and $88 \%$ for $\mathrm{CNB}$ alone to $100 \%$ when using both techniques together [60]. Since the utility of FNAB of the breast is on the decline and is being replaced by CNB in many institutions, Nassar [61], in her elegant review, emphasized the importance of FNAB of the breast and the utility of new modalities to help overcome its limitations when compared to CNB. She also reminded all of us in the field of cytology that utilizing new modalities in conjunction with fine-needle aspiration will potentially decrease the limitations of fine-needle aspiration alone. The incidence of inadequate specimens is lower in CNB than FNAB. In their study on nonpalpable breast lesions, Ibrahim et al. [62] demonstrated a high inadequacy rate for FNAB (58.7\%). In another study on nonpalpable breast lesions, FNAB was inadequate in $22 \%$ of the cases [63].

Sung et al. [47] demonstrated that CNB and FNAB/ $\mathrm{CNB}$ were significantly more accurate for diagnosing thyroid malignancies than FNAB alone, and that combined FNAB/CNB was more accurate for thyroid malignancy than CNB alone in small thyroid nodules of less than $1 \mathrm{~cm}$. The authors suggested that adding CNB could reduce the nondiagnostic or atypical cells of undetermined significance/follicular lesion of undetermined significance cases of the Bethesda system for reporting thyroid cytology.

The current standard of care in the diagnosis and subtyping of lymphomas requires the utilization of morphol- 


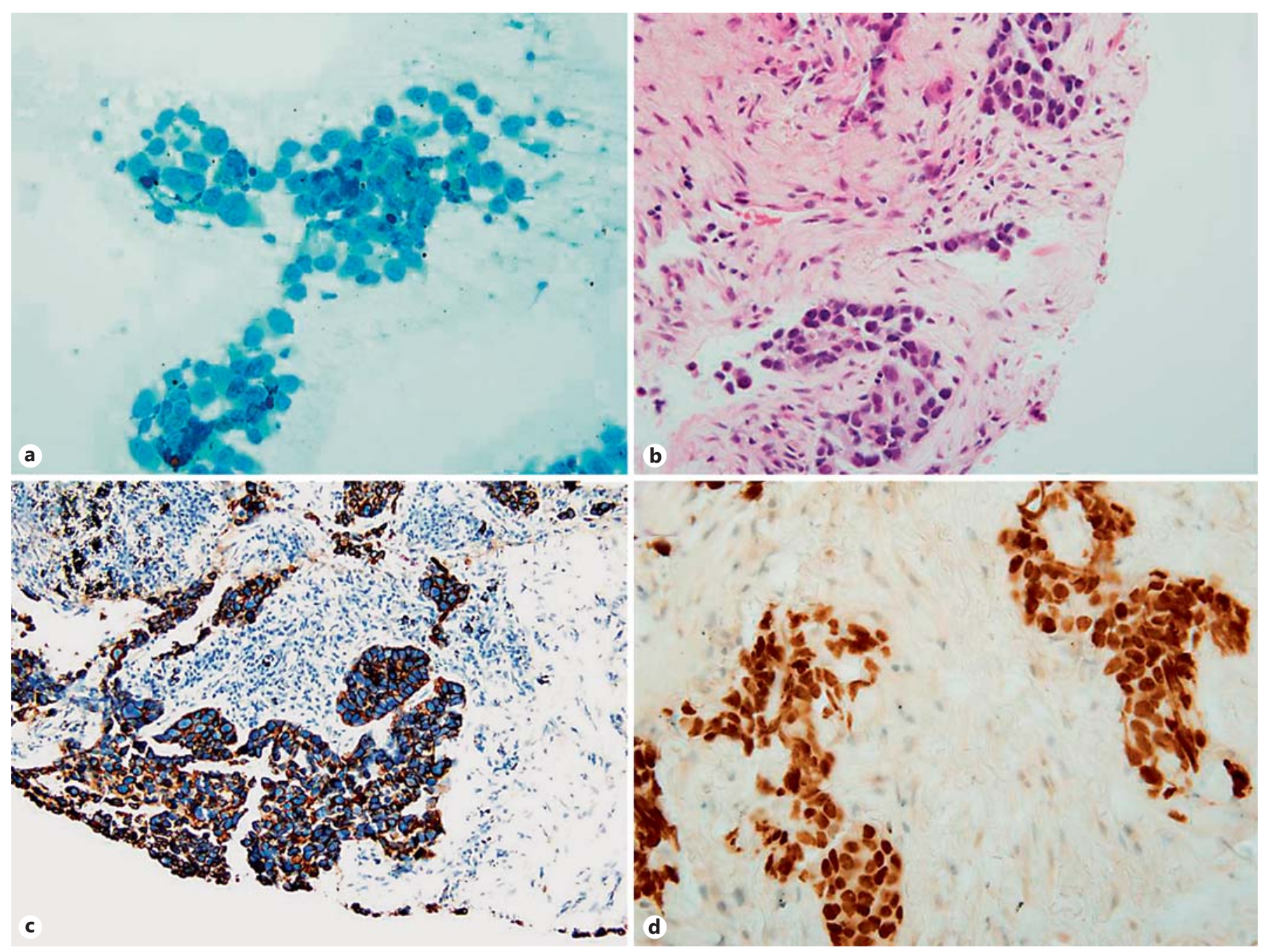

Fig. 6. CT-guided fine-needle aspiration of the lesion on the left side revealed large atypical cells with glandular differentiation (a) where the tumor was also seen on core biopsy (b). The tumor cells were immunoreactive for CK7 (c) and TTF-1 (d), confirming the primary nature of this adenocarcinoma.

ogy, immunophenotyping and molecular findings. As demonstrated by many, some of these features can be achieved by FNAB [64-67]. However, in some cases FNAB may not be adequate enough to provide all these requirements, mandating a core or open biopsy. Consequently, FNAB of lymph nodes provides adequate material for flow-cytometric immunophenotyping, while CNB allows the assessment of lymph node architecture and helps in the confirmation and subtyping of many lymphomas through immunohistochemistry [68-73]. In a large retrospective study aimed to evaluate the diagnostic accuracy of combined FNAB and CNB in diagnosing lymphomas, Amador-Ortiz et al. [68] demonstrated that 237 out of 263 cases were diagnosed and 193 (75\%) cases were completely subclassified (96.5\% sensitive and $100 \%$ specific). The authors concluded that combined FNAB and $\mathrm{CNB}$ with ancillary studies provides a valuable alternative to excisional biopsies for the diagnosis of lymphoma. Other studies reported a higher diagnostic rate of lymphoma by CNB ranging between 80 and 90\% [69-72]. In a recent comprehensive review, Dr. Caraway demonstrated the evolving role of FNAB in diagnosing lymphoproliferative disorders [74].

In a prospective study on 57 excised renal masses, Barwari et al. [75] demonstrated that combing FNAB and $\mathrm{CNB}$ in the evaluation of such masses improved the accuracy rate by about $3.5-14 \%$ when compared to FNAB or CNB alone. After surgical excision, the specimens were 


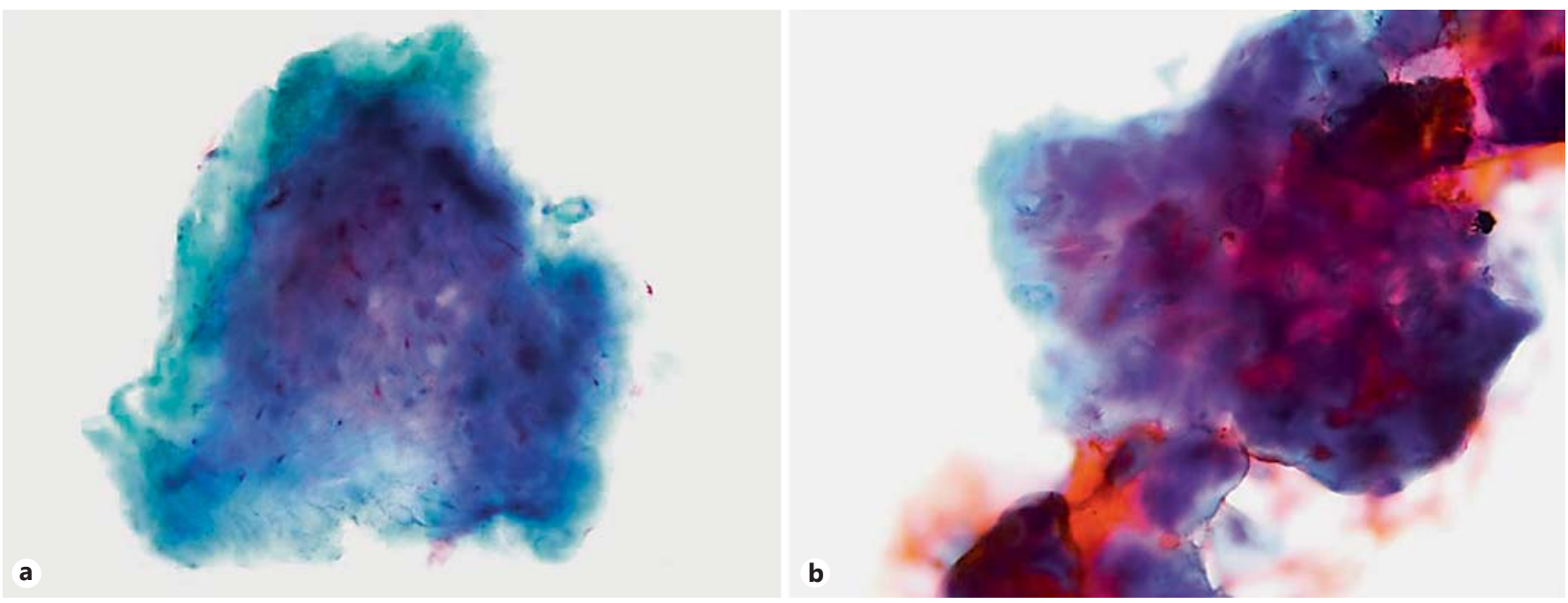

Fig. 7. The lesion on the right side was also targeted by CT-guided FNAB followed by core biopsy and proved to be a benign hamartoma. Papanicolaou- (a) and Diff-Quik-stained smears (b); both showed myxoid and cartilaginous material, and the core had similar features.

examined in the pathology department where the urologist performed two CNBs using 18-gauge needles and subsequently performed FNAB using a 22-gauge needle before subjecting the specimen for routine and standard histological examination. Five pathologists participated in this study and all of them reached a consensus on the final histological diagnosis of these specimens. This consensus diagnosis was considered the final gold standard and reference diagnosis against which the accuracy of the FNAB and CNB interpretations were measured. They found that the diagnostic accuracy rate using $\mathrm{CNB}$ and FNAB together ranged from 89.5 to $98.2 \%$, while for CNB alone was from 80.7 to $89.5 \%$ and for FNAB the accuracy ranged from 71.9 to $93 \%$. In another study intended to evaluate the value of combined FNAB and CNB in the evaluation of small solid renal tumors, Li et al. [45] showed that the diagnostic accuracy for the combined procedure and for CNB was $100 \%$, while it was $88 \%$ for FNAB.

In our routine daily practice we believe that the combined procedure helps to retain experience in the cytology of solid organs and provide maximum sensitivity and specificity. FNAB and CNB techniques should not be considered mutually exclusive, but as two different diagnostic modalities that complement one another [76-79]. We have encountered cases where the diagnostic material was only seen in the FNAB material, while in others it was more evident in the CNB material (fig. 4-7). Table 4 summarizes the advantages of the combined procedure. Therefore, and as shown by other investigators, the
Table 4. Advantages of the combined approach

Increases the accuracy of diagnosis, especially in small lesions

Provides more material for additional ancillary studies

Both FNAB and CNB are complementary to each other and allow better interpretation of morphology and architecture

Increases the sensitivity and the specificity of either approach alone

More convenient to the patient

More satisfaction for clinicians who are still hesitant to manage their patients based on cytological material alone

It builds greater experience in cytology for those pathologists who believe more in tissue diagnosis

It helps when there are very complex lesions, such as composite malignancies

utilization of both aspirate smears and core tissue biopsy material are complementary and have added value compared to either one alone $[7,13,26,29,33,35,38,39$, $44-47,50-52,57-62,68,75-78]$.

The final argument that can be made against the combined approach is adding cost, especially in the current era of cost containment. An additional cost will be added when an additional core biopsy is performed, but on the other hand this approach will be cheaper than having a 
second procedure, whether a repeat fine-needle aspiration or core biopsy. In addition, since 'patient-centered medicine' is a prime target of almost all health institutions, it makes tremendous sense to be able to provide a highly diagnostic procedure in one setting for our patients. Despite the fact that our current hospital is a ministry of health institution, we attempted to perform a cost analysis study to compare the cost of FNAB followed by a second $\mathrm{CNB}$ procedure at a later date to reach a better or more accurate diagnosis, and compared that to utilizing the combined approach in one setting. The result of our simple analysis was based on the assumption that if we had to bring $40 \%$ of our patients back for a CNB after an initial $\mathrm{FNAB}$, and compared that with the combined approach in the same setting for those $40 \%$, we found that the combined approach would create a cost saving of at least $17 \%$.

\section{Conclusions}

The adoption of this combined diagnostic strategy of FNAB followed by CNB supplemented by on-site evaluation and immediate triaging by a pathologist is a cost- effective approach that saves the patient unnecessary additional clinic visits and procedures, and reduces the number of false-negative results. It is easy to perform and time saving. Optimization of the diagnostic yield is highly dependent on an organized coordination among radiologists, pathologists and clinicians. Uniform guidelines for optimal tissue retrieval and triaging should be placed for each institution. We believe that the combined FNAB/CNB approach is reasonable and a logical technique, and we recommend its adoption as a diagnostic tool.

\section{Acknowledgments}

The authors thank Mr. Lambert T. Porter, section head of Quality and Strategic Planning (QSPA) at our hospital for his valuable help in the cost analysis.

\section{Disclosure Statement}

The authors declare no conflict of interest of any sort. No grants or funding were needed to complete this project.

\section{References}

-1 Simsir A, Rapkiewicz A, Cangiarella J: Current utilization of breast FNA in a cytology practice. Diagn Cytopathol 2009;37:140-142.

$\checkmark 2$ Manfrin E, Mariotto R, Remo A, Reghellin D, et al: Is there still a role for fine-needle aspiration cytology in breast cancer screening? Experience of the Verona Mammographic Breast Cancer Screening Program with realtime integrated radiopathologic activity (1999-2004). Cancer 2008;114:74-82.

-3 Eisele DW, Sherman ME, Koch WM, Richtsmeier WJ, Wu AY, Erozan YS: Utility of immediate on-site cytopathological procurement and evaluation in fine needle aspiration biopsy of head and neck masses. Laryngoscope 1992;102:1328-1330.

$\checkmark 4$ Saleh HA, Khatib G: Positive economic and diagnostic accuracy impacts of on-site evaluation of fine needle aspiration biopsies by pathologists. Acta Cytol 1996;40:1227-1230.

$>5$ Nasuti JF, Gupta PK, Baloch ZW: Diagnostic value and cost-effectiveness of on-site evaluation of fine-needle aspiration specimens: review of 5,688 cases. Diagn Cytopathol 2002; 27:1-4.

-6 Silverman JF, Finley JL, O’Brien KF, Dabbs DJ, et al: Diagnostic accuracy and role of immediate interpretation of fine needle aspiration biopsy specimens from various sites. Acta Cytol 1989;33:791-796.
7 Schoellnast H, Komatz G, Bisail H, Talakic E, et al: CT-guided biopsy of lesions of the lung, liver, pancreas or of enlarged lymph nodes: value of additional fine needle aspiration (FNA) to core needle biopsy (CNB) in an offsite pathologist setting. Acad Radiol 2010;17:1275-1281.

-8 Axe SR, Erozan YS, Ermatinger SV: Fine-needle aspiration of the liver: a comparison of smear and rinse preparations in the detection of cancer. Am J Clin Pathol 1986;86:281-285.

-9 Schwerk WB, Dürr HK, Schmitz-Moormann P: Ultrasound guided fine-needle biopsies in pancreatic and hepatic neoplasms. Gastrointest Radiol 1983;8:219-225.

10 Chiu KW, Chang-Chien CS, Chen L, Liaw YF: Ultrasonically-guided needle aspiration with preparation of cell blocks in the diagnosis of liver tumors. Hepatogastroenterology 1994; 41:30-33.

11 Orell SR, Sterrett GF, Walters MNI, et al: Manual and atlas of fine needle aspiration cytology, ed 3. London, Churchill Livingstone, 1999, pp 267-290.

12 Jain D, Mathur SR, Iyer VK: Cell blocks in cytopathology: a review of preparative methods, utility in diagnosis and role in ancillary studies. Cytopathology 2014;25:356-371.
13 Barth RJ Jr, Merino MJ, Solomon D, Yang JC, Baker AR: A prospective study of the value of core needle biopsy and fine needle aspiration in the diagnosis of soft tissue masses. Surgery $1992 ; 112: 536-543$

14 Goudy SL, Flynn MB: Diagnostic accuracy of palpation-guided and image-guided fine-needle aspiration biopsy of the thyroid. Ear Nose Throat J 2005;84:371-374.

15 Mehrotra P, Hubbard JG, Johnson SJ, Richardson DL, Bliss R, Lennard TW: Ultrasound scan-guided core sampling for diagnosis versus freehand FNAC of the thyroid gland. Surgeon 2005;3:1-5.

16 Izquierdo R, Arekat MR, Knudson PE, Kartun $\mathrm{KF}$, et al: Comparison of palpation-guided versus ultrasound-guided fine-needle aspiration biopsies of thyroid nodules in an outpatient endocrinology practice. Endocr Pract 2006;12:609-614.

17 Nayar R, Ivanovic M: The indeterminate thyroid fine-needle aspiration: experience from an academic center using terminology similar to that proposed in the 2007 National Cancer Institute Thyroid Fine Needle Aspiration State of the Science Conference. Cancer 2009; 117:195-202. 
-18 Yassa L, Cibas ES, Benson CB, Frates MC, et al: Long-term assessment of a multidisciplinary approach to thyroid nodule diagnostic evaluation. Cancer 2007;111:508-516.

$\checkmark 19$ Hatada T, Okada K, Ishii H, Ichii S, Utsunomiya J: Evaluation of ultrasound-guided fine-needle aspiration biopsy for thyroid nodules. Am J Surg 1998;175:133-136.

20 Yang J, Schnadig V, Logrono R, Wasserman PG: Fine-needle aspiration of thyroid nodules: a study of 4703 patients with histologic and clinical correlations. Cancer 2007;111: 306-315.

21 Gharib H, Papini E, Paschke R, Duick DS, et al; AACE/AME/ETA Task Force on Thyroid Nodules: American Association of clinical Endocrinologists, Associazione Medici Endocrinologi, and European Thyroid Association medical guidelines for clinical practice for the diagnosis and management of thyroid nodules. Endocr Pract 2010;16:1-43.

-22 Radkay LA, Chiosea SI, Seethala RR, Hodak SP, LeBeau SO, Yip L, McCoy KL, Carty SE, Schoedel KE, Nikiforova MN, Nikiforov YE, Ohori NP: Thyroid nodules with KRAS mutations are different from nodules with NRAS and HRAS mutations with regard to cytopathologic and histopathologic outcome characteristics. Cancer Cytopathol 2014;122:873882.

-23 Yip L, Wharry LI, Armstrong MJ, Silbermann A, McCoy KL, Stang MT, Ohori NP, LeBeau SO, Coyne C, Nikiforova MN, Bauman JE, Johnson JT, Tublin ME, Hodak SP, Nikiforov YE, Carty SE: A clinical algorithm for fineneedle aspiration molecular testing effectively guides the appropriate extent of initial thyroidectomy. Ann Surg 2014;260:163-168.

-24 Nikiforov YE, Ohori NP, Hodak SP, Carty SE LeBeau SO, Ferris RL, Yip L, Seethala RR, Tublin ME, Stang MT, Coyne C, Johnson JT, Stewart AF, Nikiforova MN: Impact of mutational testing on the diagnosis and management of patients with cytologically indeterminate thyroid nodules: a prospective analysis of 1056 FNA samples. J Clin Endocrinol Metab 2011;96:3390-3397.

-25 Nikiforov YE, Carty SE, Chiosea SI, Coyne C, Duvvuri U, Ferris RL, Gooding WE, Hodak SP, LeBeau SO, Ohori NP, Seethala RR, Tublin ME, Yip L, Nikiforova MN: Highly accurate diagnosis of cancer in thyroid nodules with follicular neoplasm/suspicious for a follicular neoplasm cytology by ThyroSeq v2 next-generation sequencing assay. Cancer 2014;120:3627-3634.

26 Cusick JD, Dotan J, Jaecks RD, Boyle WT Jr: The role of Tru-Cut needle biopsy in the diagnosis of carcinoma of the breast. Surg Gynecol Obstet 1990;170:407-410.

27 Japanese Breast Cancer Society: General Rules for Clinical and Pathological Recording of Breast Cancer, ed 16. Breast cytology and core needle biopsy reporting form (in Japanese). Tokyo, JBCS, 2008, pp 64-74.
8 Park IA, Ham EK: Fine needle aspiration cytology of palpable breast lesions: histologic subtype in false negative cases. Acta Cytol 1997;41:1131-1138.

29 Rautiainen S, Masarwah A, Sudah M, Sutela A, Pelkonen O, Joukainen S, Sironen R, Kärjä V, Vanninen R: Axillary lymph node biopsy in newly diagnosed invasive breast cancer: comparative accuracy of fine-needle aspiration biopsy versus core-needle biopsy. Radiology 2013;269:54-60.

30 Cools-Lartigue J, Sinclair A, Trabulsi N, Meguerditchian A, Mesurolle B, Fuhrer R, Meterissian S: Preoperative axillary ultrasound and fine-needle aspiration biopsy in the diagnosis of axillary metastases in patients with breast cancer: predictors of accuracy and future implications. Ann Surg Oncol 2013;20: 819-827.

- 31 Al Mushawah F, Tan MC, Margenthaler JA: Axillary staging prior to or after neoadjuvant systemic therapy? A single institutional experience. J Surg Oncol 2010;102:404-407.

32 Ali SZ, Parwani AV: Breast Cytopathology: Essentials in Cytopathology. New York, Springer, 2007, pp 1-15.

33 Pilgrim S, Ravichandran D: Fine needle aspiration cytology as an adjunct to core biopsy in the assessment of symptomatic breast carcinoma. Breast 2005;14:411-414.

34 Fornage BD: Sonographically guided needle biopsy of nonpalpable breast lesions. J Clin Ultrasound 1999;27:385-398.

35 Britton PD: Fine needle aspiration or core biopsy. Breast 1999;8:1-4.

- 36 Monaco SE, Khalbuss WE, Pantanowitz L: Benign non-infectious causes of lymphadenopathy: a review of cytomorphology and differential diagnosis. Diagn Cytopathol 2012; 40:925-938.

37 Meyer L, Gibbons D, Ashfaq R, Vuitch F, Saboorian $\mathrm{MH}$ : Fine-needle aspiration findings in Castleman's disease. Diagn Cytopathol 1999;21:57-60.

38 Thanos L, Galani P, Mylona S, Pomoni M, Mpatakis N: Percutaneous CT-guided core needle biopsy versus fine needle aspiration in diagnosing pneumonia and mimics of pneumonia. Cardiovasc Intervent Radiol 2004;27: 329-334.

39 Bennert KW, Abdul-Karim FW: Fine needle aspiration cytology vs. needle core biopsy of soft tissue tumors: a comparison. Acta Cytol 1994;38:381-384

40 Matsumoto K, Ashizawa K, Tagawa T, Nagayasu T: Chest wall implantation of thymic cancer after computed tomographyguided core needle biopsy. Eur J Cardiothorac Surg 2007;32:171-173.

41 UyBico SJ, Motamedi K, Omura MC, Nelson SD, Eilber FC, Eckardt J, Seeger LL: Relevance of compartmental anatomic guidelines for biopsy of musculoskeletal tumors: retrospective review of 363 biopsies over a 6 -year period. J Vasc Interv Radiol 2012;23:511-518.e2.
42 Uematsu T, Kasami M: Risk of needle tract seeding of breast cancer: cytological results derived from core wash material. Breast Cancer Res Treat 2008;110:51-55.

43 Chao C, Torosian MH, Boraas MC, Sigurdson ER, Hoffman JP, Eisenberg BL, Fowble B: Local recurrence of breast cancer in the stereotactic core needle biopsy site: case reports and review of the literature. Breast J 2001;7:124127.

44 Nagar S, Iacco A, Riggs T, Kestenberg W, Keidan R: An analysis of fine needle aspiration versus core needle biopsy in clinically palpable breast lesions: a report on the predictive values and a cost comparison. Am J Surg 2012;204:193-198.

$45 \mathrm{Li} \mathrm{G}$, Cuilleron M, Zhao A, Obadia F, et al: Combination of core biopsy and fine-needle aspiration increases diagnostic rate for small solid renal tumors. Anticancer Res 2012;32: 3463-3466.

46 Renshaw AA, Pinnar N: Comparison of thyroid fine-needle aspiration and core needle biopsy. Am J Clin Pathol 2007;128:370-374.

$\checkmark 47$ Sung JY, Na DG, Kim KS, Yoo H, et al: Diagnostic accuracy of fine-needle aspiration versus core-needle biopsy for the diagnosis of thyroid malignancy in a clinical cohort. Eur Radiol 2012;22:1564-1572.

48 Klein JS, Salomon G, Stewart EA: Transthoracic needle biopsy with a coaxially placed 20 -gauge automated cutting needle: results in 122 patients. Radiology 1996;198:715-720.

49 Chung T: Fine needle aspiration of the solitary pulmonary nodule. Semin Thorac Cardiovasc Surg 2002;14:275-280.

50 Boiselle PM, Shepard JA, Mark EJ, Szyfelbein WM, et al: Routine addition of an automated biopsy device to fine-needle aspiration of the lung: a prospective assessment. AJR Am J Roentgenol 1997;169:661-666.

51 Kraft M, Laeng H, Schmuziger N, Arnoux A, Gürtler N: Comparison of ultrasound-guided core-needle biopsy and fine-needle aspiration in the assessment of head and neck lesions. Head Neck 2008;30:1457-1463.

52 Gong Y, Sneige N, Guo M, Hicks ME, Moran CA: Transthoracic fine-needle aspiration vs concurrent core needle biopsy in diagnosis of intrathoracic lesions: a retrospective comparison of diagnostic accuracy. Am J Clin Pathol 2006;125:438-444.

53 Rekhtman N, Brandt SM, Sigel CS, Friedlander MA, Riely GJ, Travis WD, Zakowski MF, Moreira AL: Suitability of thoracic cytology for new therapeutic paradigms in non-small cell lung carcinoma: high accuracy of tumor subtyping and feasibility of EGFR and KRAS molecular testing. J Thorac Oncol 2011;6: 451-458.

54 Ocque R, Tochigi N, Ohori NP, Dacic S: Usefulness of immunohistochemical and histochemical studies in the classification of lung adenocarcinoma and squamous cell carcinoma in cytologic specimens. Am J Clin Pathol 2011;136:81-87. 
55 da Cunha Santos G, Lai SW, Saieg MA, Geddie WR, Pintilie M, Tsao MS, Boerner SL, Hwang D: Cyto-histologic agreement in pathologic subtyping of non small cell lung carcinoma: review of 602 fine needle aspirates with follow-up surgical specimens over a nine year period and analysis of factors underlying failure to subtype. Lung Cancer 2012;77:501506.

56 Schneider F, Smith MA, Lane MC, Pantanowitz L, Dacic S, Ohori NP: Adequacy of core needle biopsy specimens and fine-needle aspirates for molecular testing of lung adenocarcinomas. Am J Clin Pathol 2015;143:193200; quiz 306.

-57 Yang YJ, Damron TA: Comparison of needle core biopsy and fine-needle aspiration for diagnostic accuracy in musculoskeletal lesions. Arch Pathol Lab Med 2004;128:759-764.

58 Bandyopadhyay S, Pansare V, Feng J, AliFehmi R, et al: Frequency and rationale of fine needle aspiration biopsy conversion to core biopsy as a result of onsite evaluation. Acta Cytol 2007;51:161-167.

59 Dalén BP, Meis-Kindblom JM, Sumathi VP, Ryd W, Kindblom LG: Fine-needle aspiration cytology and core needle biopsy in the preoperative diagnosis of desmoid tumors. Acta Orthop 2006;77:926-931.

-60 Poole GH, Willsher PC, Pinder SE, Robertson JF, Elston CW, Blamey RW: Diagnosis of breast cancer with core-biopsy and fine needle aspiration cytology. Aust NZ J Surg 1996; 66:592-594.

-61 Nassar A: Core needle biopsy versus fine needle aspiration biopsy in breast: a historical perspective and opportunities in the modern era. Diagn Cytopathol 2011;39:380-388.

-62 Ibrahim AE, Bateman AC, Theaker JM, Low $\mathrm{JL}$, et al: The role and histological classification of needle core biopsy in comparison with fine needle aspiration cytology in the preoperative assessment of impalpable breast lesions. J Clin Pathol 2001;54:121-125.
63 Salami N, Hirschowitz SL, Nieberg RK, Apple SK: Triple test approach to inadequate fine needle aspiration biopsies of palpable breast lesions. Acta Cytol 1999;43:339-343.

64 Monaco SE, Teot LA, Felgar RE, Surti U, Cai G: Fluorescence in situ hybridization studies on direct smears: an approach to enhance the fine-needle aspiration biopsy diagnosis of $\mathrm{B}$ cell non-Hodgkin lymphomas. Cancer 2009; 25;117:338-348.

65 Zeppa P, Vigliar E, Cozzolino I, Troncone G, Picardi M, De Renzo A, Grimaldi F, Pane F, Vetrani A, Palombini L: Fine needle aspiration cytology and flow cytometry immunophenotyping of non-Hodgkin lymphoma: can we do better? Cytopathology 2010;21: 300-310.

66 da Cunha Santos G, Ko HM, Geddie WR, Boerner SL, Lai SW, Have C, Kamel-Reid S, Bailey D: Targeted use of fluorescence in situ hybridization (FISH) in cytospin preparations: results of 298 fine needle aspirates of $\mathrm{B}$-cell non-Hodgkin lymphoma. Cancer $\mathrm{Cy}$ topathol 2010;118:250-258.

67 Zeppa P, Sosa Fernandez LV, Cozzolino I, Ronga V, Genesio R, Salatiello M, Picardi M, Malapelle U, Troncone G, Vigliar E: Immunoglobulin heavy-chain fluorescence in situ hybridization-chromogenic in situ hybridization DNA probe split signal in the clonality assessment of lymphoproliferative processes on cytological samples. Cancer Cytopathol 2012;120:390-400

68 Amador-Ortiz C, Chen L, Hassan A, Frater $\mathrm{JL}$, et al: Combined core needle biopsy and fine-needle aspiration with ancillary studies correlate highly with traditional techniques in the diagnosis of nodal-based lymphoma. Am J Clin Pathol 2011;135:516-524.

69 Zinzani PL, Colecchia A, Festi D, Magagnoli $\mathrm{M}$, et al: Ultrasound-guided core-needle biopsy is effective in the initial diagnosis of lymphoma patients. Haematologica 1998; 83 : 989-992.

70 Demharter J, Neukirchen S, Wagner T, Schlimok G, Bohndorf K, Kirchhof K: Do ultrasound-guided core needle biopsies of lymph nodes allow for subclassification of malignant lymphomas? (In German.) Rofo 2007;179: 396-400.
1 Agid R, Sklair-Levy M, Bloom AI, Lieberman $\mathrm{S}$, et al: CT-guided biopsy with cutting-edge needle for the diagnosis of malignant lymphoma: experience of 267 biopsies. Clin Radiol 2003;58:143-147.

72 Pappa VI, Hussain HK, Reznek RH, Whelan J, et al: Role of image-guided core-needle biopsy in the management of patients with lymphoma. J Clin Oncol 1996;14:2427-2430.

73 Ben-Yehuda D, Polliack A, Okon E, Sherman $\mathrm{Y}$, et al: Image-guided core-needle biopsy in malignant lymphoma: experience with 100 patients that suggests the technique is reliable. J Clin Oncol 1996;14:2431-2434.

74 Caraway NP: Evolving role of FNA biopsy in diagnosing lymphoma: past, present, and future. Cancer Cytopathol 2015;123:389-393.

75 Barwari K, Kummerlin IP, ten Kate FJ, Algaba $\mathrm{F}$, et al: What is the added value of combined core biopsy and fine needle aspiration in the diagnostic process of renal tumours? World J Urol 2013;31:823-827.

-76 Kurita T, Tsuchiya S, Watarai Y, Yamamoto $\mathrm{Y}$, et al: Roles of fine-needle aspiration and core needle biopsy in the diagnosis of breast cancer. Breast Cancer 2012;19:23-29.

77 Garg S, Mohan H, Bal A, Attri AK, Kochhar S: A comparative analysis of core needle biopsy and fine-needle aspiration cytology in the evaluation of palpable and mammographically detected suspicious breast lesions. Diagn Cytopathol 2007;35:681-689.

78 Hatada T, Ishii H, Ichii S, Okada K, Fujiwara Y, Yamamura T: Diagnostic value of ultrasound-guided fine-needle aspiration biopsy, core-needle biopsy, and evaluation of combined use in the diagnosis of breast lesions. J Am Coll Surg 2000;190:299-303.

-79 Kocjan G, Bourgain C, Fassina A, Hagmar B, et al: The role of breast FNAC in diagnosis and clinical management: a survey of current practice. Cytopathology 2008;19:271-278. 